\title{
Análise da expansão do espaço urbano do município de Campina Grande-PB tendo o sistema de transportes como agente modificador
}

\author{
Analysis of urban expansion of space in the city Campina Grande-PB having \\ transport system modifier as agent \\ Madson T. Silva* ${ }^{* 1}$, Stephanny C. F. do E. Costa ${ }^{2}$, Edicarlos P. de Sousa ${ }^{3}$, \\ Sonaly D. de Oliveira ${ }^{4}$, Vicente de Paulo R. da Silva ${ }^{5}$ \\ ${ }^{1}$ Departamento de Engenharia Civil, Universidade Federal do Rio Grande do Norte, Lagoa Nova, Brasil \\ ${ }^{2} \mathrm{UAEC} / \mathrm{CTRN} / \mathrm{UFCG}$ \\ 3,4,5UACA/CTRN/UFCG
}

\begin{abstract}
Resumo
Esse trabalho objetiva analisar a inter-relação transportes - expansão urbana e a metodologia utilizada constou da realização de um levantamento bibliográfico para a fundamentação teórica do estudo e análise de imagens de satélite, a partir do TM/LANDSAT 5 (1989 e 2007), disponibilizadas no site http://www.dpi.inpe.br, do Instituto Nacional de Pesquisas Espaciais (INPE), para se detectar a evolução e a tendência de ocupação da área do município, de obtenção de dados de transportes, de informações e representações georeferenciadas da delimitação política do município e de seus respectivos bairros, da malha viária, do uso e da ocupação do solo e zoneamento geoeconômico fornecido pela Secretaria de Planejamento de Campina Grande (SEPLAN), a fim de se obter informações sobre o planejamento e a gestão urbana. Nesse contexto, o sensoriamento remoto e o geoprocessamento apresentam-se como ferramentas de grande importância para o estudo da dinâmica de transportes focada no desenvolvimento da cidade, tendo em vista que é possível obter imagens multitemporais e informações cadastrais. Em suas conclusões, esse trabalho mostra a relevância do planejamento de transportes para a cadeia produtiva e social, num misto de gestão administrativa e crescimento urbano, demonstrando que investimento no setor de transportes também está associado ao bem estar e à qualidade de vida.
\end{abstract}

Palavras-chave: urbanização, planejamento de transportes, sensoriamento remoto

\begin{abstract}
This work aims to analyze the transport - urban expansion interrelation. The methodology consisted of: a bibliographical survey to support the theoretical approach; the study and analysis of the TM/LANDSAT 5 (1989 e 2007) satellite images, available at the National Institute of Space Research (INPE) - http://www.dpi.inpe.br, to detect the evolution and tendency of the city area occupation; georeferenced information and representations of the city's political boundaries, as well as its districts; the road network; the land use and the geoeconomic zoning provided by the Secretary of Planning Department of Campina Grande (SEPLAN), in order to obtain information about planning and urban management. In this context, remote sensing and geoprocessing become important tools to the study of transport dynamics focused on the development of the city, considering that it is possible to obtain multitemporary images and cadastral information. In its conclusions, this work shows the relevance of transportation planning for the production and social chains in a mix of administrative management and urban growth, demonstrating that investment in the transport sector is also related to the well being and quality of life.
\end{abstract}

Keywords: Urbanization, transportation planning, remote sensing

*madson_tavares@hotmail.com

Recebido: 13/03/2014 Aceito: 13/03/2014 


\section{Introdução}

$\mathrm{N}$ os últimos anos, muitos pesquisadores têm procurado entender as mudanças temporais e espaciais nos padrões da paisagem urbana, visando obter respostas mais elucidativas sobre a dinâmica de uso do solo. A maioria dos estudos utiliza métodos para quantificar padrões através do tempo. Embora seja evidente a necessidade de abordagens complementares, que propiciem esclarecimentos sobre a dinâmica da paisagem para o gerenciamento local, poucos estudos propõem metodologias alternativas (Greenhill et. al., 2003).

A compreensão dos padrões de mudanças, de suas causas e consequências sócias ambientais, deverá conduzir ao aprimoramento da capacidade de predizer dinâmicas futuras e estabelecer diretrizes e ações para o gerenciamento local (Kienast, 1993). Isso é especialmente importante em área urbana, onde os conflitos frequentemente surgem em decorrências às múltiplas demandas sociais, econômicas e ambientais (Turner, 1996).

$\mathrm{O}$ ordenamento territorial, no qual se inclui o planejamento do uso do solo, é um processo de apoio à administração urbanística, através do qual se elaboram modelos normativos específicos denominados planos (Pardal et al., 1993). Os planos caracterizam-se por se referirem a determinado espaço num determinado tempo de vigência, e por conterem um componente regulamentar que enquadra e possibilita o controle das intervenções sobre o território.

Neste contexto, o uso Sistemas de Informação Geográfica (SIGs), para o planejamento do uso do solo, vem se mostrando, cada vez mais, uma ferramenta poderosa e eficiente nas diversas áreas do conhecimento. Segundo Aronoff (1989) e Bull (1994), os SIGs são sistemas automatizados usados para armazenar, analisar e manipular dados geográficos, ou seja, dados que representam objetos e fenômenos em que a localização geográfica é uma característica inerente à informação e indispensável para analisá-la. Este tipo de ferramenta revolucionou o monitoramento e a gestão dos recursos naturais e uso do solo, devido à capacidade de análise de grande quantidade de informação de diversas origens, de for-

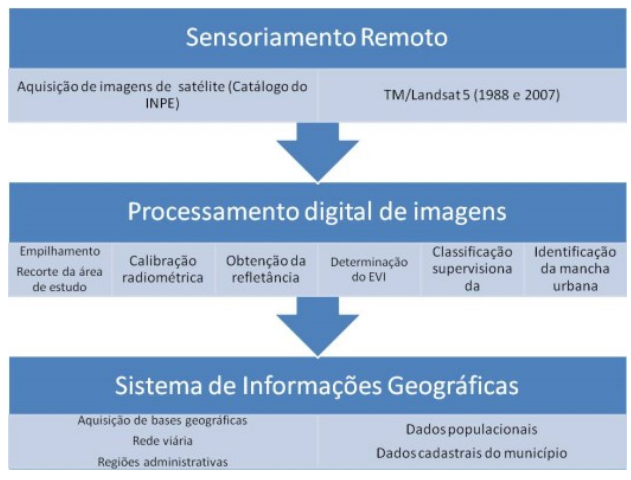

ma simultânea. Não se torna, portanto, surpreendente que recentemente tenha havido um crescente interesse na utilização de ferramentas com recurso de SIG como um suporte de apoio à decisão (Eastman et al., 1993).

$\mathrm{Na}$ área de transporte evidencia-se a utilização de SIG como ferramenta de auxílio para resolução de diferentes tipos de problemas: gerência de pavimentos, transporte coletivo, rodoviário e de carga, engenharia do tráfego, localização de facilidades e planejamento de transportes. (Meneses, 2003).

A análise espacial, em muitos casos, não se verifica por se tratar, apenas, de uma informação associada a uma rede ou um espaço territorial. Porém, já existem alguns trabalhos em que se procura verificar uma correlação entre o valor do dado e sua localização no espaço geográfico. Como exemplo de aplicação de um SIG na análise espacial num projeto de planejamento de transportes tem-se o plano de transportes na cidade de Bauru-São Paulo (Raia, 2000).

Forster (1994) afirma que o sensoriamento remoto surge como uma técnica alternativa e bastante eficiente para avaliar o processo de crescimento do espaço urbano. Esta técnica, aliada a outras tecnologias, fornece a possibilidade de monitorar, além do crescimento urbano, os problemas ambientais decorrentes do processo de expansão da mancha urbana.

Neste particular, o objetivo do presente artigo é identificar a influência dos sistemas de transportes no crescimento e consumo do espaço urbano no município de Campina Grande - PB, com base em imagens do Maneador Temático do Landsat 5, dados de crescimento urbano e do setor de transportes.

\section{Material e métodos}

Para verificar a influência dos sistemas de transportes no crescimento e consumo do espaço urbano no município de Campina Grande - PB, o estudo compreendeu as seguintes etapas: (I) Aquisição e processamento digital de imagens do Mapeador Temático do satélite Landsat 5; (II) Aquisição de bases geográficas e dados referentes às características da malha viária, densidade demográ-

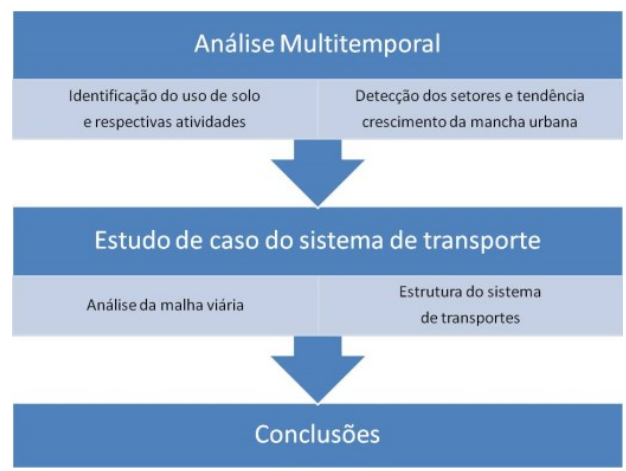

Figura 1. Fluxograma de resolução do estudo. 
fica, mudanças referentes ao uso do solo e principais sistemas de transportes do município; e (III) Análise multitemporal dos resultados por meio da integração entre as informações obtidas (Figura 1).

\section{Caracterização da área de estudo}

A sede do município de Campina Grande está situada na Mesorregião Geográfica do Agreste Paraibano, na Zona Centro Oriental da Paraíba, no planalto da Borborema. A cidade de Campina Grande apresenta uma localização com certo privilégio em relação à equidistância aos principais centros do Nordeste, com 7º 13' 50' de latitude Sul e 35은 $52^{\prime}$ $52^{\prime \prime}$ de longitude Oeste de Greenwich (Figura 2), distante $124 \mathrm{~km}$ da Capital do Estado, os principais acessos à sede do Município são as Rodovias Federais BR 230 (Transamazônica) e a BR 104, que cruzam a cidade no sentido Leste-Oeste e Norte-Sul, respectivamente; e a BR 412, que faz conexão com o Cariri e interior de Pernambuco. Campina Grande é o segundo município em população e exerce grande influência política e econômica sobre outros 57 municípios do Estado da Paraíba. Este conjunto de municípios é denominado de Compartimento da Borborema e é constituído de 5 microrregiões conhecidas como Agreste da Borborema, Brejo Paraibano, Cariris Velhos, Seridó Paraibano e Curimatá. O município de Campina Grande e sua zona urbana apresentam, respectivamente, áreas de 621 km² e $98 \mathrm{~km}^{2}$, aproximadamente.

\section{Aspectos socioeconômicos}

O município foi criado em 1788, a população total para o ano de 2010 é de 385.276 habitantes, sendo mais de $95 \%$ na área urbana. Seu Índice de Desenvolvimento Humano (IDH) é de 0.721. Existem 2.634 leitos hospitalares, em 133 estabelecimentos de saúde, sendo 82 estabelecimentos prestadores de serviços ao SUS (Sistema Único de Saúde). O ensino fundamental tem 80.427 matrículas e o ensino médio 19.764; Presença de unidades de ensino superior. Os programas ou ações na área de geração de trabalho e renda são: incentivos para atração de atividades econômicas, benefício tributário relativo ao IPTU, benefício tributário relativo ao ISS, cessão de terras, fornecimento de infraestrutura, programa de geração de trabalho e renda e capacitação profissional. Verifica-se descentralização administrativa com a formação de conselhos nas áreas de educação, saúde, assistência social, emprego/ trabalho, turismo, meio ambiente, transportes, política urbana ou desenvolvimento urbano e orçamento. Outros conselhos de política setoriais e fundo municipal nas áreas de educação, saúde, assistência social, turismo, cultura, meio ambiente e transportes. Existem centros sócio-culturais como bibliotecas públicas, museus, teatros ou salas de espetáculos, cinemas, clubes e associações recreativas, estádios ou ginásios poliesportivos, estações de rádio AM e FM, geradora de TV e provedor de Internet (IBGE, 2011).

\section{Processamento digital de imagens}

Para a realização deste estudo foram utilizadas duas imagens geradas pelo Mapeador Temático do satélite Landsat cinco, compostas de sete bandas espectrais, cujas principais características estão descritas na Tabela 1. Essas imagens correspondem à passagem do Landsat 5 - TM sobre a área de estudo, nos dias 10 de julho de 1989(Figura 2) e para o dia 29 de agosto de 2007 (Figura

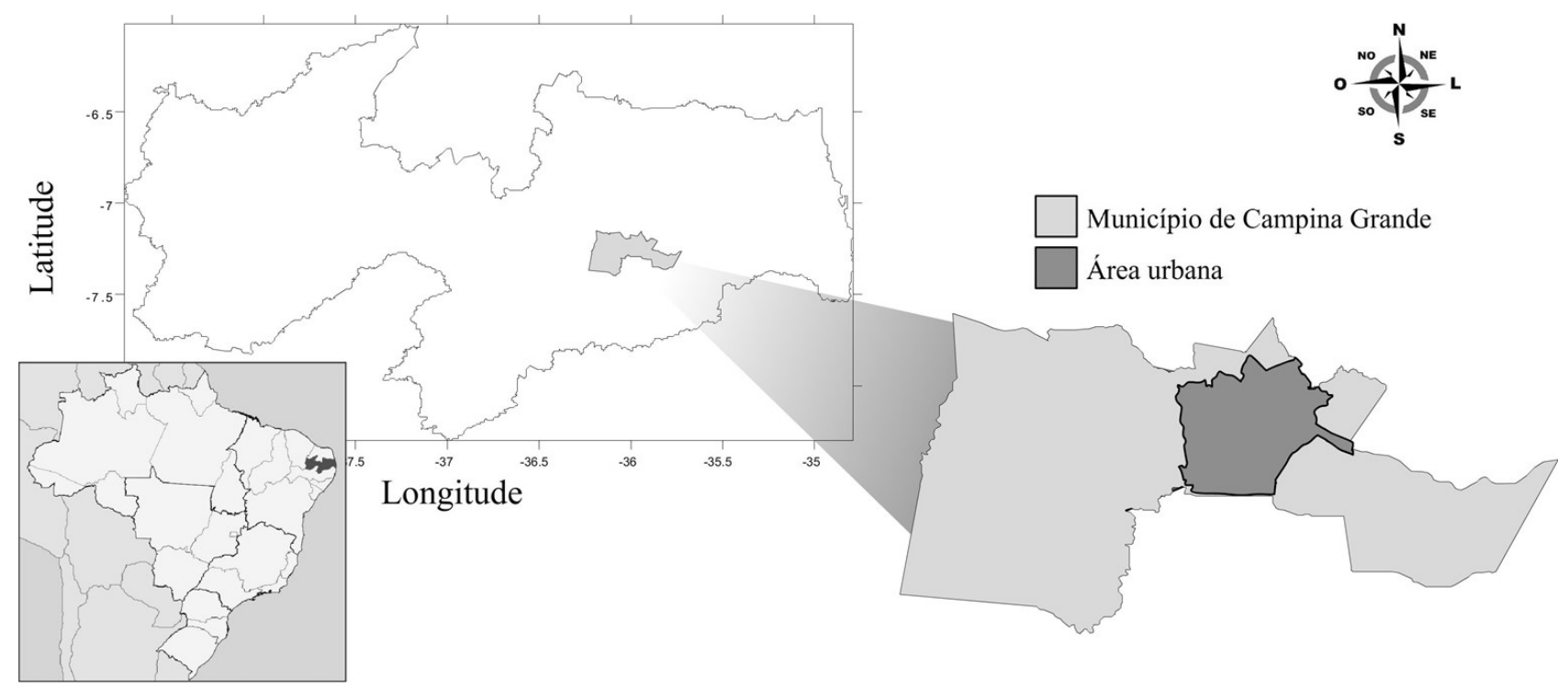

Figura 2. Localização geográfica da área de estudo. 
Tabela 1. Descrição dos canais do Mapeador Temático (TM) do Landsat 5, com os correspondentes coeficientes de calibração (radiância mínima - a e máxima - b) e irradiâncias espectrais no topo da atmosfera (TOA).

\begin{tabular}{cccc}
\hline Banda & $\boldsymbol{a}\left(\mathbf{W m}^{-\mathbf{2}} \mathbf{s r}^{-\mathbf{1}} \boldsymbol{\mu \mathbf { m } ^ { - 1 } )}\right.$ & $\boldsymbol{b}\left(\mathbf{W m}^{-\mathbf{2}} \mathbf{s r}^{-\mathbf{1}} \boldsymbol{\mu \mathbf { m } ^ { - 1 } )}\right.$ & $\boldsymbol{K}_{\boldsymbol{\lambda} \boldsymbol{i}}\left(\mathbf{W m}^{-\mathbf{2}} \boldsymbol{\mu \boldsymbol { m } ^ { - \mathbf { 1 } } )}\right.$ \\
\hline 1 & $-1,52$ & 193,0 & 1957 \\
2 & $-2,84$ & 365,0 & 1826 \\
3 & $-1,17$ & 264,0 & 1554 \\
4 & $-1,51$ & 221,0 & 1036 \\
5 & $-0,37$ & 30,2 & 215,0 \\
6 & 1,2378 & 15,303 & - \\
7 & $-0,15$ & 16,5 & 80,67 \\
\hline
\end{tabular}

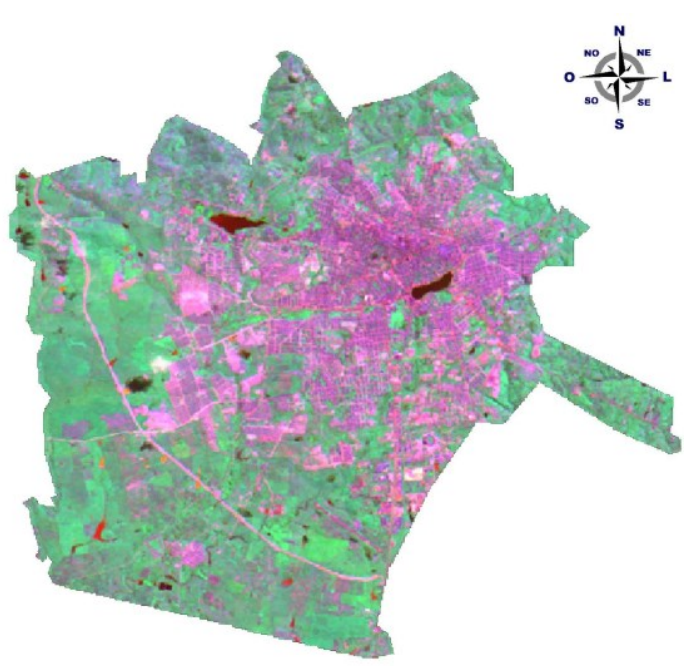

Figura 3. Imagem TM/Landsat cinco em composição das bandas (RGB345) referente à área de estudo no dia 10/07/1989.

3), na órbita 214 e ponto 65 . Neste estudo foi utilizado o software ERDAS 9.2, para obtenção do EVI, na construção do banco de dados geográficos e na integração de todas as informações disponíveis da área de estudo.

Para diferenciação da área urbana dos demais tipos de cobertura de solo para o período estudado, foi utilizado o índice de vegetação EVI. Tal índice foi formulado a partir de uma combinação de outros dois índices de vegetação: o SAVI (Soil-Adjusted Vegetation Index; Huete, 1988) e o ARVI (Atmosphere Resistant Vegetation Index; Kaufman \& Tanré, 1992), tendo a finalidade de atenuar os efeitos do solo e da atmosfera sobre o monitoramento da vegetação, de acordo com a Equação (1):

$$
E V I=G * \frac{(N I R-\text { Vermelho })}{(L+N I R+C 1 * \text { Vermelho }-C 2 * A z u l)}
$$

Onde: NIR = refletância no infravermelho próximo; Vermelho = refletância no vermelho; Azul = refletância no azul; $\mathrm{C} 1$ = coeficiente de correção dos efeitos atmos-

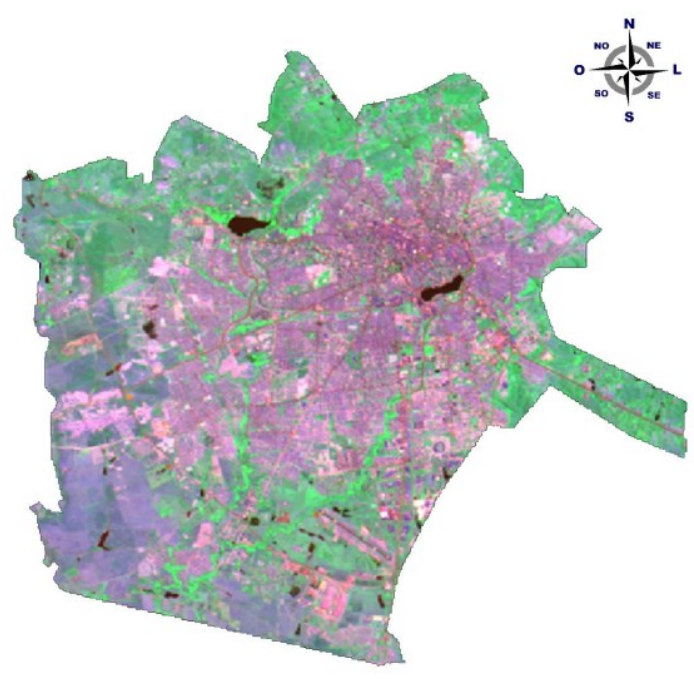

Figura 4. Imagem TM/Landsat 5 em composição das bandas (RGB345) referente à área de estudo no dia 29/08/2007.

féricos para a banda do vermelho (6); $\mathrm{C} 2$ = coeficiente de correção dos efeitos atmosféricos para a banda do azul $(7,5) ; \mathrm{L}=$ fator de correção para a interferência do solo (1); $\mathrm{G}=$ fator de ganho $(2,5)$. Os coeficientes C1 e C2 podem ser alterados de acordo com condições regionais.

A partir das cartas do EVI foi possível identificar com mais nitidez as diferentes classes de cobertura do solo, sendo, então, possível aplicar o processo da classificação de cada pixel. Desse modo, foram geradas duas cartas temáticas de cobertura de solo do município, tornando possível quantificar as classes temáticas nas duas datas de estudo. A quantificação das áreas das classes existentes foi obtida gerando-se um plano de informação contendo a frequência de cada classe do EVI. Para a classificação das imagens foi adotado o algoritmo da Máxima Verossimilhança (MAXVER), em que considera a ponderação das distâncias entre médias dos níveis de cinza das classes (Leão et al., 2007). Para o mapeamento temático do estudo em questão, quatro classes foram definidas: Água superficial, área urbana, vegetação e solo exposto. Consideraram-se áreas urbanas como as 
áreas que compreendem maior densidade populacional, incluindo núcleos urbanos. As Figuras 5 e 6 apresentam os produtos finais do processamento digital das imagens.

\section{Resultados e discussão}

Para que se pudesse ter uma visão espacial do crescimento da mancha urbana de Campina Grande - PB, inicialmente foram produzidos mapas temáticos (Figuras 5 e 6), produtos da classificação supervisionada do índice de vegetação EVI, que foi obtido a partir do processamento digital das imagens de satélite. De acordo com as Figuras 5 e 6 é possível observar a expansão da área urbana do município de Campina Grande-PB entre o período de 1989 e 2007. Observa-se maior adensamento urbano na região do entorno do Açude Velho, localizado no centro comercial da cidade (ver Figura 10), todavia as regiões sul e sudoeste apresentaram nos últimos anos maior tendência de ocupação. As Figuras 5 e 6 também permitem a análise conjunta do desenvolvimento urbano e/ou populacional do município, pois se sabe que a ocupação do solo é fator determinante para a caracterização do espaço urbano e a formulação de diretrizes das necessidades de planejamento e infraestrutura de transportes.

Observa-se pela Tabela 2 a evolução da população do município de Campina Grande - PB para o período de 1970 a 2008. Em 1970, a população era de 197.802 habitantes com uma densidade demográfica na área urbana de 1.729,35 hab. $\mathrm{km}^{-2}$; já para ano de 2008 estes mesmos indicadores são de 381.422 hab. e 3.700,57 hab.

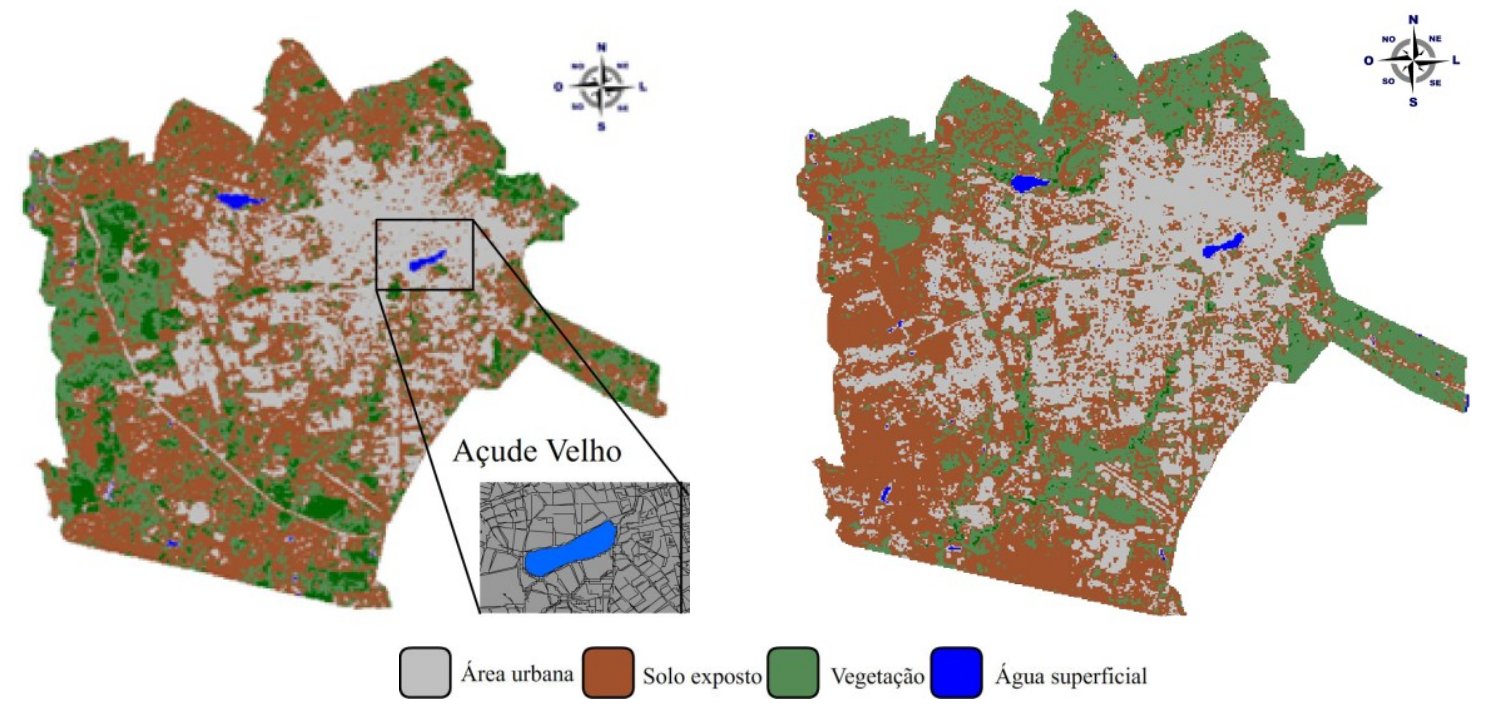

Figura 5. Mapa temático da ocupação do solo

Figura 6. Mapa temático da ocupação do solo referente à área de estudo no dia 10/07/1989. referente à área de estudo no dia 29/08/2007.

Tabela 2. Evolução da população da área urbana do município de Campina Grande - PB.

\begin{tabular}{cccc}
\hline Ano & No habitante & $\begin{array}{c}\text { População } \\
\text { Urbana (hab.) }\end{array}$ & $\begin{array}{c}\text { Hab. } \\
\text { urbano/km }\end{array}$ \\
\hline 1970 & 197.802 & $85,68 \%$ & $1.729,35$ \\
\hline 1980 & 247.964 & $92,07 \%$ & $2.329,60$ \\
\hline 1991 & 326.307 & $94,23 \%$ & $3.137,54$ \\
\hline 1996 & 344.730 & $94,28 \%$ & $3.316,44$ \\
\hline 2000 & 355.331 & 94,98 & $3.443,81$ \\
\hline 2007 & 371.060 & $95,03 \%$ & $3.598,15$ \\
\hline 2008 & 381.422 & $95,08 \%$ & $3.700,57$ \\
\hline 2010 & 385.276 & - & - \\
\hline
\end{tabular}

Fonte: http://www.ibge.gov.br IBGE - Censo Demográfico, 1970/1980/1991/1996 e 2007 ( ${ }^{*}$ contagem populacional) 
$\mathrm{km}^{-2}$. Com isso é possível observar que a população praticamente duplicou no período de 40 anos. Tal crescimento é justificado pela forte atratividade da cidade, exercida por sua função de pólo regional, em razão de sua posição geográfica estratégica de entreposto entre a Região do Cariri, o Sertão e o Litoral paraibano, e por ser, essa cidade, um centro universitário e tecnológico de destaque. As correntes imigratórias de população da área rural, muito presentes até início dos anos 80, também impulsionaram o crescimento da sua mancha urbana, registrando uma intensa e rápida transformação, a partir nos anos 1970, de glebas rurais em loteamentos urbanos na periferia da cidade, com variações bastante significativas nas diversas localidades que compõem sua malha urbana, típica de uma estrutura sócio-espacial segregada (Carvalho \& Scocuglia - 2008).
A dinâmica na ocupação do espaço é verificada pela Figura 7, que representa o esquema da expansão do município de Campina Grande-PB entre os anos de 1918 (em destaque) e 2007. Verifica-se, primeiramente, que a ocupação se deu em torno do Açude Velho, em função da disponibilidade de uma fonte de água para as atividades humanas e após nove décadas a mancha expandiu-se de forma a alcançar cerca de $98 \mathrm{~km}^{2}$. Dados da Secretaria de Planejamento de Campina Grade (SEPLAN, 2010) refletem o quadro urbano do município, caracterizado pela acelerada e desarticulada ocupação do território passando, em 1980, de apenas 03 grandes favelas para a atual existência de 38 áreas de habitação precária, 739 cortiços, com um déficit habitacional de mais de 12.000 moradias e inúmeros parcelamentos irregulares caracterizados pelo uso e ocupação desorde-

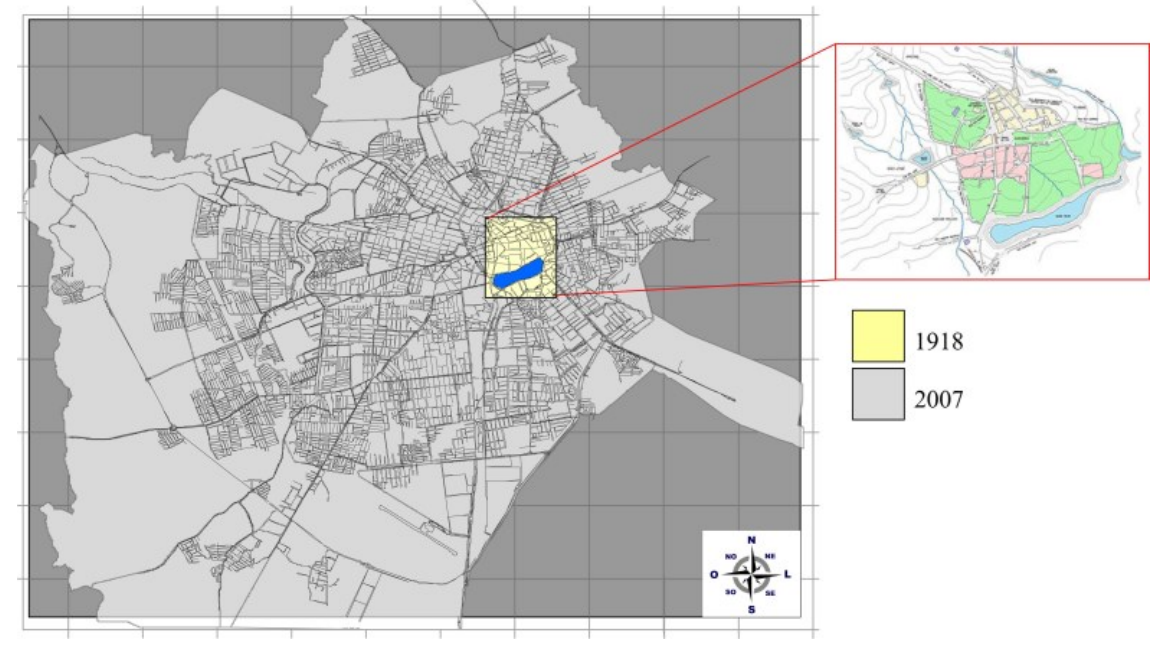

Figura 7. Esquema da expansão do município de Campina Grande - PB.

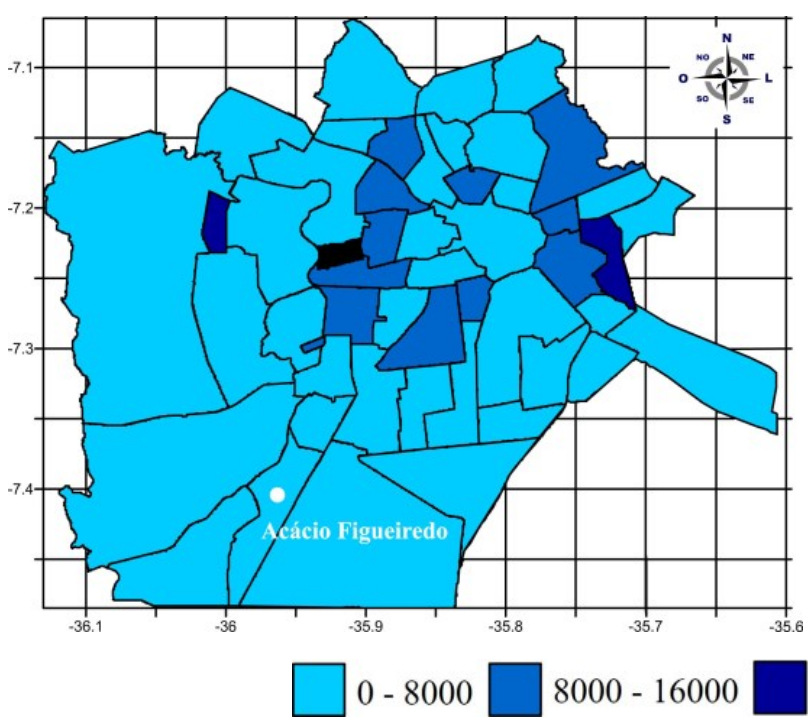

Figura 8. Densidade demográfica da área urbana do município de Campina Grande-PB, segundo dados de 1991.

Fonte: SEPLAN - PMCG

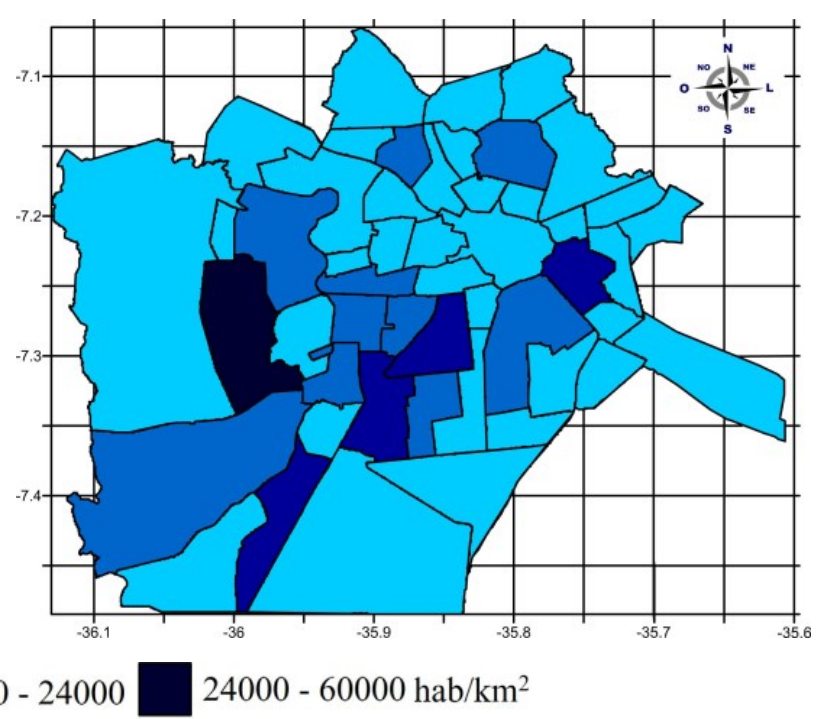

Figura 9. Densidade demográfica da área urbana do município de Campina Grande-PB, segundo dados de 2007.

Fonte: SEPLAN - PMCG 
nada do solo, comprometimento ambiental do território, ocupação inadequada de áreas de proteção e deterioração da estrutura urbana existente.

Os mapas temáticos de densidade demográfica da área urbana do município de Campina Grande-PB (Figuras 8 e 9) para o período de 1991 a 2007, respectivamente, refletem a tendência de ocupação do espaço que, em sua maior parte, está localizada na periferia.

De modo geral, observa-se que os bairros próximos ao centro comercial da cidade apresentam maior taxa de densidade demográfica que variam entre 8000 a 16000 hab. $\mathrm{km}^{-2}$, todavia para o ano de 2007 (Figura 9) é notória a tendência de ocupação para os bairros periféricos, justificada principalmente pelas atividades de trabalho, educação, lazer, saúde, entre outros.

Esse fato é verificado para o bairro Acácio Figueiredo, próximo ao pólo industrial da cidade (ver Figura 10), que apresentava taxa de densidade demográfica de 0 a 8000 hab. $\mathrm{km}^{-2}$ no ano de 1991, enquanto este mesmo índice está entre 16000 a 24000 hab. $\mathrm{km}^{-2}$ para o ano de 2007. Em geral, zonas com maior densidade demográfica necessitam da implantação de novas vias ou reestruturação das existentes para que a malha viária seja capaz de proporcionar mobilidade e acessibilidade das zonas produtoras para as atrativas de viagens.

Bittencourt \& Brizon (2006) consideram o setor de transporte como uma atividade complementar às demais atividades econômicas e sociais de uma região, porém de presença constante no cotidiano das pessoas que se deslocam motivadas por trabalho, saúde, estudos, compras ou lazer. Nesses termos, a atratividade de uma região é tanto melhor quanto maior for seu acesso às demais. Através da Figura 10, pode-se verificar que a dinâmica de ocupação do espaço urbano dá-se de forma seletiva, de modo que na zona central a atividade comercial juntamente com os setores de serviço público são os principais mecanismos de ocupação do espaço. A

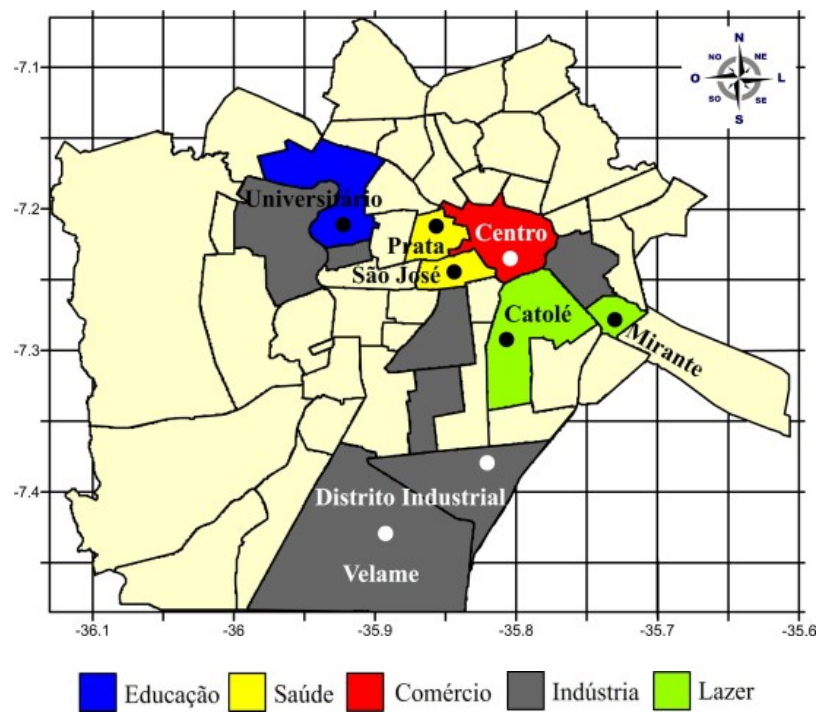

Figura 10 - Características da ocupação do solo do município de Campina Grande - PB.
Figura 10 também permitiu a identificação, com bases em dados obtidos da SEPLAN, de zonas específicas geradoras de viagens. Tais zonas estão caracterizadas, principalmente, por serviços de educação superior (bairro Universitário), saúde (Prata e São José), indústria (Velame e Distrito Industrial) e lazer (Catolé e Mirante). Desta forma, o mapa de uso do solo é uma fonte para a obtenção da localização da demanda potencial (usuários) de cada região da cidade. A Figura 11 exibe a tendência de consumo do espaço urbano mostrado pelas setas, sendo resultado da análise conjunta das Figuras 5 e 6. A análise conjunta das Figuras 10 e 11 reforça a necessidade da integração entre a ocupação do espaço e o planejamento de transporte, que devem acontecer de forma coesa, tendo em vista que a distribuição do sistema de transportes precisa contemplar, de forma satisfatória, as regiões que possuem os maiores potenciais para o desenvolvimento residencial.

A Figura 12 mostra a malha viária da área urbana do município de Campina Grande-PB. Pode-se notar que duas rodovias federais cruzam a cidade (BR 230 e BR 104), também foi possível observar que a principal via arterial, Av. Marechal Floriano Peixoto, cruza a área urbana do município no sentido Nordeste - Sudoeste, suportando altos volumes de tráfego e ligando o centro aos principais bairros da cidade, sendo interceptadas pelas vias coletoras que facilitam o acesso dentro das zonas. Todo esse conjunto é responsável pela mobilidade da área urbana do município. É importante frisar que o maior número de vias está em zonas de maior densidade demográfica, mas que elas nem sempre suportam o tráfego de forma satisfatória, principalmente pelo aumento considerável de automóveis e motocicletas nos últimos anos.

Em 2008 o município construiu seu terminal de integração (em destaque na Figura 12c) que, de forma

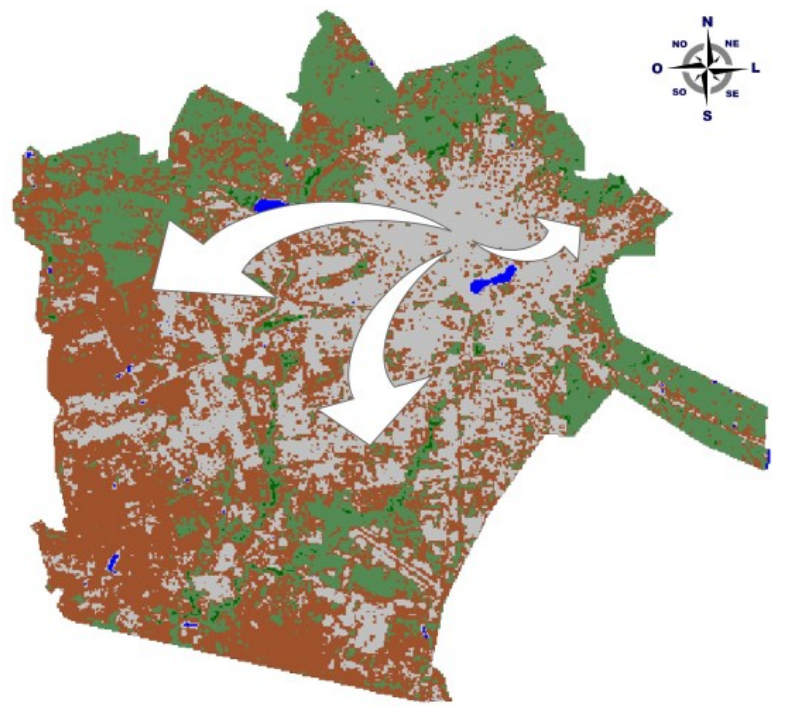

Figura 11. Tendência de consumo do espaço urbano no município de Campina Grande - PB entre os anos de 1989 e 2007. 

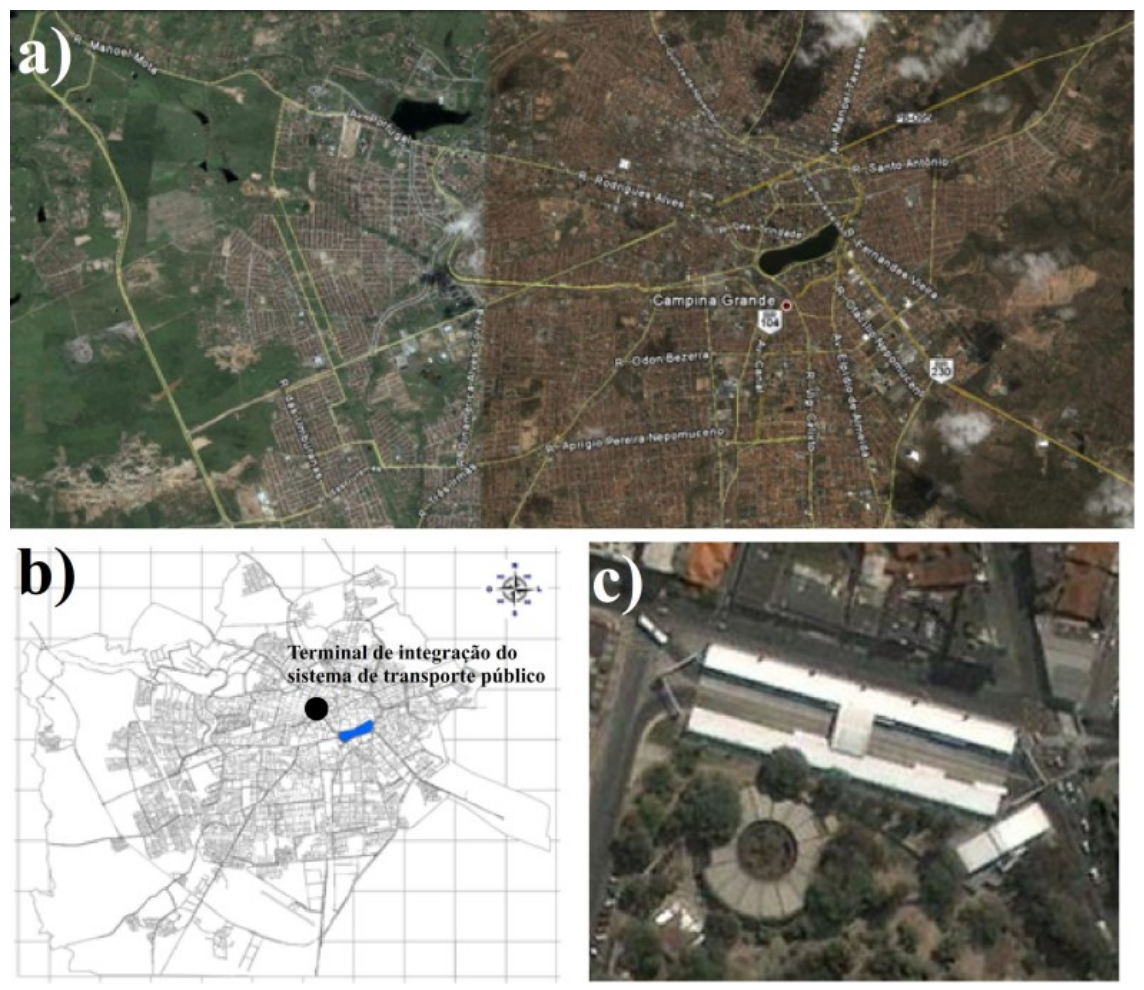

Figura 12. Vista aérea das principais vias da cidade de Campina Grande-PB (a), sistema viário da cidade segundo dados de 2011 e localização do terminal de integração do sistema de transporte público (b) e vista aérea do terminal de integração do sistema de transporte público (c).

Tabela 3. Perfil de passageiros e característica do sistema de transportes por ônibus no município de Campina Grande - PB para o dia 14 de março de 2011.

\begin{tabular}{lccccccc}
\hline $\begin{array}{l}\text { Principais } \\
\text { Rotas }\end{array}$ & $\begin{array}{c}\text { No de veículos/ } \\
\text { Dia útil }\end{array}$ & $\begin{array}{c}\text { Tempo } \\
\text { De viagem } \\
\text { (min) }\end{array}$ & Km & $\begin{array}{c}\text { Viagens/ } \\
\text { Dia }\end{array}$ & Passageiros & Estudantes & Gratuitos \\
\hline Linha: $903 B$ & $\mathbf{4}$ & 90 & 33,00 & 62 & 4.529 & 1.166 & 0 \\
\hline Linha: 955 & $\mathbf{4}$ & 90 & 40,00 & 63 & 2.791 & 421 & 0 \\
\hline Linha: 263A & $\mathbf{6}$ & 84 & 25,94 & 63 & 4.389 & 1.093 & 0 \\
\hline Linha: 263B & $\mathbf{6}$ & 84 & 25,07 & 58 & 4.622 & 1.311 & 0 \\
\hline Linha: 092 & $\mathbf{5}$ & 61 & 33,63 & 79 & 5.064 & 1.042 & 0 \\
\hline Linha: 500 & $\mathbf{4}$ & 60 & 20,06 & 62 & 3.162 & 1.262 & 0 \\
\hline Linha: 505 & $\mathbf{6}$ & 74 & 24,85 & 72 & 3.853 & 822 & 0 \\
\hline Linha: 555 & $\mathbf{6}$ & 82 & 23,11 & 72 & 3.850 & 737 & 0 \\
\hline Linha: 101 & $\mathbf{8}$ & 88 & 26,4 & 86 & 4.287 & 869 & 0 \\
\hline Linha: 111 & $\mathbf{6}$ & 88 & 25,16 & 50 & 4.469 & 887 & 0 \\
\hline Linha: 303 & $\mathbf{5}$ & 78 & 20,74 & 71 & 5.261 & 2.052 & 0 \\
\hline Linha: 333 & $\mathbf{4}$ & 78 & 24,14 & 63 & 4.433 & 1.632 & 0 \\
\hline Linha: 004 & $\mathbf{8}$ & 77 & 27,03 & 79 & 4.035 & 1.091 & 0 \\
\hline Linha: 404 & $\mathbf{7}$ & 77 & 24,88 & 88 & 4.497 & 926 & 0 \\
\hline Linha: 444 & $\mathbf{7}$ & 77 & 23,94 & 85 & 4.629 & 1.042 & 0 \\
\hline Linha: 901 & $\mathbf{5}$ & 55 & 14,81 & 87 & 3.196 & 830 & 44 \\
\hline Linha: 077 & $\mathbf{3}$ & 70 & 19,54 & 72 & 4.076 & 996 & 7 \\
\hline
\end{tabular}


satisfatória, permitiu ligar as principais linhas de ônibus da cidade e, devido a sua posição estratégica de estar inserido no centro comercial, minimizar o problema de deslocamento entre as zonas residenciais e as zonas atrativas de viagens. A análise global da malha viária da cidade permite dizer que o crescimento populacional se deu anteriormente à infraestrutura de transportes, caracterizando, assim, o desordenamento das vias públicas e frisando a falta de planejamento urbano.

Observam-se pela Tabela 3 as características do sistema de transportes por ônibus no município de Campina Grande - PB, em março 2011. A linha verde (rotas 303 e 333), que tem como itinerários as regiões leste e oeste da cidade, concentra o maior número do total de passageiros, cerca de $20 \%$ do total dos 89.373 transportados pelas principais rotas. Esta mesma linha transporta cerca de $20 \%$ do total de 18.179 estudantes; esta porcentagem utiliza a linha verde como principal rota de acesso a escolas e às principais universidades da cidade. As informações referentes ao sistema de transporte são de grande importância para o entendimento do deslocamento e a eficiência de cobertura quanto ao tipo de ocupação do espaço, pois conhecida a demanda de determinada atividade, pode-se implantar um sistema de transporte mais eficaz e mais barato.

Segundo Sousa Neto \& Lima (2010) estudos sobre áreas metropolitanas indicam que os deslocamentos pendulares tornam-se indicadores da centralização de atividades numa região, isto é, da dinâmica da vida social, econômica e cultural. São tais deslocamentos que caracterizam a vida urbana atual, acentuando a importância dos transportes para viabilizar tal processo.

\section{Conclusões}

A realização desse trabalho levou à constatação de que a cidade de Campina Grande - PB, que teve seu início a partir do Açude Velho, passou a apresentar crescimento urbano desordenado, dificultando a execução de ações simultâneas de planejamento urbano com o de transportes. Esse fato é facilmente notado pela atual defasagem do sistema de transportes em relação ao que ele deveria prover.

A tendência de consumo do espaço urbano deve ser analisada anteriormente a intervenções no sistema de transportes, tendo em vista que quanto mais acelerado for o crescimento da população, mais rápido os instrumentos viabilizadores de mobilidade se tornarão defasados, trazendo, então, apenas soluções a curto prazo.

Portanto, é de grande relevância um planejamento de transportes para a cadeia produtiva e social, num misto de gestão administrativa e crescimento urbano, demonstrando que investimento no setor de transportes também está associado ao bem estar e à qualidade de vida.

\section{Referências}

ARONOFF, S. Geographic Information Systems. WDL. Publications, Canada. 1989.

BITTENCOURT, F. S.; BRIZON, L. C. Transporte metroferroviário e desenvolvimento urbano. II Concurso de Monografia CBTU 2006 - A cidade nos trilhos, 2006. Disponível em: <http://www.cbtu.gov. br/monografia/2006/trabalhos/fernandodesenna. pdf $>$ Acesso em: 20 set. 2010.

BULL, G. Ecosystem Modelling with GIS. Environmental Management, 18(3): 345-349, 1994.

CARVALHO, M. J. F.; SCOCUGLIA, J. B. Novos discursos, velhos problemas: políticas urbanas e planejamento em Campina Grande-PB (1970-2005). Revista Alpharrabios, v.02, n.01, p.1-15, 2008

EASTMAN, J. R.; JIN, W; KYEM, P.A.K.; TOLEDANO, J. GIS AND DECISION MAKING,. IN.

Explorations in geographic information system technology. Genebra: UNITAR, v.04, pp.112, 1993.

FORSTER, B. C. An examination of some problems and solutions in urban monitoring from satellite platforms. International Journal of Remote Sensing, v.06, n.01, p.139-151, 1994 .

GREENHILL, D. R.; RIPKE, L. T. HITCHMAN, A. P.; JONES, G. A.; WILKINSON, G.G. Characterization of Suburban Areas for Land Use Planning Using Landscape Ecological Indicators

Sensing. v.41, n.09, p.2015-2021, 2003.

HUETE, A. R. Adjusting vegetation indices for soil influences. International Agrophysics, v.04, n.04, p.367-376, 1988 .

IBGE (2011). Instituto Brasileiro de Geografia e Estatísticas. Disponível em: <http://www.ibge.gov. br/> Acesso em: 20 fev. 2011.

IBGE (2000). Instituto Brasileiro de Geografia e Estatísticas. Setores censitários de 2000. Disponível em : <www.ibge.gov.br> Acesso em: 15 fev. 2011.

IBGE (2008). Instituto Brasileiro de Geografia e Estatísticas. Contagem da população para o ano de 2008. Disponível em: <www.ibge.gov.br> Acesso em: 15 fev. 2011. 
KAUFMAN, Y. J.; TANRE, D. Atmospheric resistant vegetation index (ARVI) for EOS-MODIS. IEEE. Transactions on Geoscience and Remote Sensing, v. 30, p. 261-270, 1992.

KIENAST, F. Analysis of historic landscape patterns with a Geographical Information System - a methodological outline.Landscape Ecology. v.08, p.103-118, 1993.

LEÃO, C.; KRUG, L. A.; KAMPEL, M.; FONSECA, L. M. G. Avaliação de métodos de classificação em imagens TM/Landsat e CCD/CBERS para o mapeamento do uso e cobertura da terra na região costeira do extremo sul da Bahia. Anais do XIII Simpósio Brasileiro de Sensoriamento Remoto (SBSR), Florianópolis: INPE, p. 939-946, 2007.

MENESES, H. B. Interface Lógica em Ambiente SIG para Bases de Dados de Sistemas Centralizados de Controle do Tráfego Urbano em Tempo Real, Dissertação de Mestrado, Centro de Tecnologia, Universidade Federal do Ceará, Fortaleza. 2003

PARDAL, S.; CORREIA, P.V.D.; LOBO, M.C. Normas Urbanísticas. Vol III. Lisboa: DGOT-UTL. 1993.

RAIA, A. A. J. Acessibilidade e Mobilidade na estimativa de um índice de potencial de viagens utilizando Redes Neurais Artificiais, Tese de Doutorado, Universidade de São Paulo, São Paulo. 2000

SEPLAN (2010). Secretaria de Planejamento do Município de Campina Grande - PB. Disponível em: <http://seplan.pmcg.pb.gov.br/> Acesso em: 20 fev. 2011.

SOUSA NETO, F. O.; LIMA, M. C. Deslocamentos cotidianos no espaço metropolitano: as trajetórias Maracanaú - Fortaleza. In. Anais do XVI Encontro Nacional dos Geógrafos, Porto Alegre: AGB, 2010.

STTP (2011). Superintendência de Trânsito e Transportes Públicos do Município de Campina Grande - PB. Disponível em: <http://sttp.pmcg. pb.gov.br /> Acesso em: 22 fev. 2011.

TURNER, M.G., WEAR, D.N. AND FLAMM, R.O. Landscape ownership and land-cover change in the southern Appalachian highlands and the Olympic Peninsula. Ecololy. Appl. v.06, p.1150-1172, 1996. 